\title{
UMA RELAÇÃO RICA E CONTROVERSA: CONSIDERAÇÕES SOBRE RONALD DWORKIN, OS POSITIVISTAS E A INTERPRETAÇÃO JURÍDICA
}

\author{
Leonardo Monteiro Crespo de Almeida*
}

\begin{abstract}
Resumo
O presente artigo busca contrapor alguns posicionamentos teóricos sustentados por Ronald Dworkin com certas considerações de autores que se identificam com a proposta teórica do positivismo jurídico. Passando pelo argumento do aguilhão semântico até a relação entre o Direito e a moral, observaremos como várias das nossas noções elementares sobre a prática jurídica podem ser bastante controversas. Os embates também tiveram papel pertinente na reformulação da interpretação jurídica: esta passa a integrar o centro das preocupações do jurista, seja ele praticante ou teórico. Antes relegada a uma atividade cuja presença só era notável diante dos casos em que a letra da lei era insuficiente para se chegar a uma conclusão satisfatória, agora a interpretação passa a abranger todo o Direito, nos fazendo repensar não apenas a dinâmica da decisão jurídica como também quais são os seus principais problemas.
\end{abstract}

Palavras-Chave: Interpretação jurídica. Decisão jurídica. Dworkin.

\section{Introdução}

O direcionamento da reflexão jurídica ao conjunto de problemas éticos relacionados ao Direito, a partir da metade do século vinte, contempla um conjunto de teorias concernentes à interpretação jurídica: apesar da diversidade de abordagens no que concerne ao conceito de interpretação e o seu objeto, questionamentos similares encontram-se presentes nas mais diversas teorias do Direito que fazem da interpretação o centro de suas reflexões. Dentre os autores da tradição jurídica anglo-saxônica que mais examinaram o papel da interpretação na prática do jurista e o seu papel na

\footnotetext{
* Doutorando em Direito pela Faculdade de Direito do Recife/UFPE. Mestre em Direito pela Faculdade de Direito do Recife/UFPE. Bacharel em Direito pelas Faculdades Integradas Barros Melo/FIBAM. Bacharel em Filosofia pela Universidade Federal de Pernambuco/UFPE. leonardoalmeida222@gmail.com.
} 
teoria do direito, Ronald Dworkin sem dúvida figura como um dos mais importantes.

Durante décadas Dworkin travou discussões com autores afiliados ao positivismo jurídico sobre as mais variadas temáticas da teoria do Direito, fortalecendo a sua teoria e chamando atenção para várias questões controversas na prática jurídica. Um exame minucioso acerca da importância desses debates é assunto que transcende o espaço de um artigo. O foco de nossa investigação consistirá, portanto, na contraposição entre essas duas perspectivas com o intuito de mostrar alguns dos principais problemas contemporâneos da teoria do direito.

A primeira parte é dividida em três seções que se entrelaçam. Na primeira, analisaremos a crítica que Dworkin faz ao positivismo jurídico hartiano tomando como fio condutor a sua pretensão descritiva, o que ficou conhecido entre teóricos do Direito como argumento do aguilhão semântico. Considerando que o caminho tomado pelos positivistas não é adequado, na seção dois veremos como Dworkin propõe uma alternativa ao reformular a relação entre Direito e interpretação. Esta é mais encarada como uma atividade prática restrita à resolução de casos complexos: o próprio conceito de Direito consiste na interpretação que fazemos de um conjunto de práticas sociais específicas.

Por fim, na terceira seção, veremos como, para Dworkin, a decisão jurídica é um empreendimento coletivo em que cada juiz realiza a sua contribuição ao mesmo tempo em que considera as demais. A interpretação do Direito pelo aplicador vai assumir um caráter holístico e normativo, ou seja, o intérprete deve ter em mente o Direito em sua totalidade, além de apresentar a melhor interpretação que pode vir a fazer dele.

$\mathrm{Na}$ segunda parte nós analisaremos algumas das objeções levantadas pelos positivistas às mencionadas posições de Dworkin. Do argumento do aguilhão semântico até a separação entre Direito e moral, e concluindo com uma reflexão crítica em torno da relação interpretação e valoração, veremos o que têm a dizer o próprio H. L. A. Hart e alguns dos autores que mais contribuíram para o avanço do positivismo jurídico, dentre eles Andrei Marmor, Brian Bix e Timothy A. O. Endicott.

R. Fac. Dir. UFG, V. 37, n. 02, p. 41 - 65, jul. / dez. $2013 \quad$ ISSN 0101 - 7187 
Na conclusão, nós optaremos por ressaltar a produtividade que surge a partir do embate de concepções teóricas distintas no campo da teoria do Direito. A elaboração de argumentos e conceitos não apenas faz com que as posições dos autores se tornem mais consistentes, como também gera repercussões significativas para a aplicação do próprio Direito, a exemplo da importância que hoje os princípios jurídicos possuem na construção jurisprudencial. As discussões também expõem o que, naquele contexto histórico, aparecem como problemas presentes em várias controvérsias entre teóricos do Direito.

\section{A busca pela superação do positivismo juridico: as posições de Ronald Dworkin acerca da interpretação}

\subsection{O Aguilhão Semântico (Semantic Sting)}

Uma das considerações mais famosas de Dworkin é a de que Direito é um conceito interpretativo: o que existe são práticas sociais e as múltiplas formas que temos de interpretá-las. O Direito como um conceito monolítico, cujo significado todos nós já temos de antemão e que encontrase para além de qualquer discussão, simplesmente é uma construção semântica desapegada do conjunto de práticas que compõem o trabalho do

jurista. Avançando um pouco mais esse último ponto, nós só poderíamos divergir acerca da aplicação do Direito caso chegássemos a um acordo em torno do que é o Direito e qual o critério adequado para a sua demarcação. Duas implicações distintas podem ser observadas.

A primeira consiste em que, apesar das divergências, os juristas concordam implicitamente sobre os critérios que possibilitam atestar se uma declaração sobre o Direito é tida verdadeira ou falsa. A segunda implica consiste em que todas as divergências acerca do Direito seriam divergências semânticas (DWORKIN, 1986, p. 45).

Os casos difíceis, por exemplo, exigiriam o exercício da discricionariedade do intérprete por conta das múltiplas possibilidades fornecidas pela estrutura semântica do texto, e pela falta de qualquer regra R. Fac. Dir. UFG, V. 37, n. 02, p. 41 - 65, jul. / dez. $2013 \quad$ ISSN 0101 - 7187 
capaz de solucioná-lo de imediato. Da vagueza chegamos à discordância, uma vez que o jurista A pode optar pelo significado Al e o jurista B poderá, em igual circunstância, optar pelo significado A2 (SHAPIRO, 2013, p.14). Qual deles estaria correto? Sobre essa situação, escreve Dworkin:

Eles [os filósofos do direito] dizem que advogados e juízes estão apenas fingindo ou que discordam apenas porque o caso com que eles se defrontam cai em uma zona cinzenta ou no limite de uma área das regras comuns. Em ambos os casos (eles dizem) é melhor ignorarmos as palavras que os juízes usam e tratá-las enquanto discordando acerca da fidelidade ou da reparação, não sobre o direito. Aí está o aguilhão: nós somos marcados como seu alvo por um retrato bastante grosseiro da discordância ou de como ela deve ser (DWORKIN, 1986, p. 46).

Dizer que uma determinada teoria do Direito é semântica, neste contexto, implica dizer que a divergência de opiniões quanto à aplicação de uma determinada regra só pode existir quando os critérios que especificam a aplicação são compartilhados entre os interlocutores, mesmo que eles, os critérios, não possam ser especificados com clareza. O principal exemplo de uma teoria do Direito semântica, para Dworkin, seria a que fora desenvolvida por H. L. A. Hart.

Uma discordância acerca de quantos livros existem em cima de uma estante só seria possível quando os interlocutores compartilham de critérios que distinguem o que conta como livro daquilo que não conta. Considerando que os critérios não são compartilhados, um interlocutor pode sustentar que existem quinze livros em cima da estante, já que conta as revistas como livros, enquanto outro dirá honestamente que existem apenas dez livros.

Haveria aqui, de fato, uma divergência sobre o número de livros, considerando que os critérios são diversos? Conforme Dworkin, o positivismo hartiano, enquanto teoria semântica, só pode conceber uma discordância genuína quando existe a aceitação, dentre os envolvidos, das chamadas regra de reconhecimento que estruturam tanto a produção quanto a aplicação dos dispositivos legais (ENDICOTT, 1998, p. 283-284). Outros R. Fac. Dir. UFG, V. 37, n. 02, p. 41 - 65, jul. / dez. $2013 \quad$ ISSN 0101 - 7187 
tipos de discussões podem ocorrer, mas não seriam aquelas que Dworkin consideraria genuínas: quando dizemos manga, nós estamos a falar da fruta ou da parte de uma roupa?

Esse tipo de abordagem chega a ser limitada inclusive nos casos em que aparentemente ela não deveria ser. Uma discussão sobre os últimos presidentes da república brasileiros precisaria ser clara se o foco vai recair no gênero sexual ou naqueles que, independente do gênero, ocuparam legitimamente a posição de chefe do poder executivo. Caso o gênero venha a contar, então a sua importância precisa ser especificada já que as discussões sobre o assunto normalmente não o tomam como critério. Em ambos os casos, no entanto, a discordância é trivial: basta o agrupamento dos fatos (as eleições) e uma contagem, e encerrada está a discussão.

Discordar sobre a quantidade de livros ou presidentes da república, fatos empiricamente comprováveis, é diferente de discordar se um governo democrático é melhor que um ditatorial (DWORKIN, 1986, p. 46). Democracia e ditadura podem ter significados diversos, alguns até obscuros, mas no emprego cotidiano, normalmente os interlocutores se encontram de acordo sobre o que cada termo significa.

Supondo, por outro lado, que antes de iniciarem uma discussão sobre democracia e Cuba, os interlocutores adquirissem um livro com inúmeras regras sobre o que é uma democracia e o que não é. Fazendo uso de dois tipos de discussões para ilustrar esse ponto: a primeira consiste em uma análise crítica do governo cubano e as liberdades que lá existem ou inexistem, enquanto a segunda versa sobre se Cuba preenche os critérios que o livro estabeleceu para que uma nação seja considerada democrática. No primeiro caso nós podemos afirmar que sim, mas a segunda discussão envolve uma discordância semântica.

Caso o interlocutor vencido se revolte, ele bem pode adquirir um outro livro de regras que possui uma visão mais ampla e peculiar da democracia, tornando-se o vencedor do debate. O ponto principal dessa controvérsia consiste em mostrar que um fato empírico (a estrutura política de Cuba) se adequa a um critério compartilhado, que por sua vez é o responsável por nos informar se um dado governo é democrático ou não. R. Fac. Dir. UFG, V. 37, n. 02, p. 41 - 65, jul. / dez. $2013 \quad$ ISSN 0101 - 7187 
Cuba e a democracia, no entanto, continuarão a ser do mesmo jeito: a discussão é apenas semântica.

Quais os melhores critérios para estabelecer se uma pena é considerada humana ou desumana: o sofrimento do preso; a comoção social; a violação de preceitos religiosos; a humilhação moral do preso? A discussão não está orientada para a comprovação de um fato, e sim para a transformação (o fim das penas cruéis?) e da maneira com que lidamos com infrações criminosas graves.

Considerando que as divergências genuínas existem quando não compartilhamos os critérios que ditariam a validade ou invalidade dos nossos enunciados, elas não podem ser dissolvidas através de um esclarecimento maior quanto ao modo em que usamos os termos nas discussões porque que já não se trata apenas da significação desses termos (DWORKIN, 1986, p. 46). Dworkin, no entanto, precisa explicar teoricamente como elas se tornam possíveis, já que a relação entre interpretação e o conjunto de práticas que permitem a concordância em torno dos significados usuais dos termos é de considerável importância para sua crítica ao positivismo jurídico, o que exige uma sustentação mais sólida.

\subsection{Interpretação Construtiva e as Práticas Sociais}

A delimitação do conceito de interpretação é por si só problemática: a sua utilização engloba os contextos práticos e as finalidades mais diversas, principalmente na história das ideias jurídicas. Um problema adicional consiste em que, se os seus contornos não se encontram bem definidos, tudo pode ser interpretação ou interpretado, tornando o conceito tão geral que sua utilização se torna desnecessária.

Poderíamos ainda acrescentar, seguindo o argumento do aguilhão semântico, a possibilidade de que, em uma dada discussão, os interlocutores utilizem o conceito de interpretação com significados discrepantes, algo bem plausível. Um interlocutor pode bem conceber a interpretação enquanto atividade voluntária, orientada para o descobrimento de algum significado oculto, enquanto outro entende a interpretação como um traço ontológico da R. Fac. Dir. UFG, V. 37, n. 02, p. 41 - 65, jul. / dez. $2013 \quad$ ISSN 0101 - 7187 
existência humana, aqui no sentido de que nós já sempre nos encontramos interpretando o mundo ao nosso redor. Dworkin distingue, em um primeiro momento, as concepções de interpretação a partir do objeto a que eles se direcionam: as ações e criações de outras pessoas distintas do intérprete, as opiniões e falas de um interlocutor, os eventos naturais.

A forma de interpretação que estamos estudando - a interpretação das práticas sociais - é como a interpretação artística neste sentido: ambas buscam interpretar algo criado por pessoas enquanto entidades distintas delas mesmas, ao invés do que as pessoas dizem, como na interpretação de uma conversa, ou eventos não criados por pessoas, como em uma interpretação científica (DWORKIN, 1986, p. 50).

Além dos diferentes objetos interpretáveis, a distinção revela algo mais: a criatividade que se faz presente na interpretação das práticas sociais e artísticas. Interpretações criativas, como as duas mencionadas, atribuem significado aos propósitos que se supõe serem os de um autor em particular, e nisso diferem de uma explicação casual, mecanicista, que gira em torno da ocorrência de eventos distintos.

A suposição do propósito é um elemento cuja conexão com a criatividade da interpretação não pode ser negligenciada: se ele já se encontra na obra ou na prática, independendo do intérprete, então a interpretação consiste em mostrar como o propósito se relaciona com as práticas, ou seja, o resultado será bem próximo ao de uma explicação casual. Seria como explicar um poema pelo estado psicológico de seu autor, ou a linguagem de Machado de Assis a partir do fato de ele ter sido carioca e mulato. O propósito em questão, nos diz Dworkin, é imposto pelo intérprete de modo que ele, o objeto interpretado, seja o melhor representante de seu gênero (DWORKIN, 1986, p. 52).

O autor destaca que, embora o intérprete atribua o propósito, ele não está livre para fazê-lo como bem entender: os constrangimentos, as limitações no âmbito de sua interpretação decorrem da forma e dos usos que compõem a prática ou o objeto. No entanto, diante de um conflito de interpretações, caso o objeto ou a prática (o dado bruto, raw data) não opte por uma das interpretações conflitantes, a escolha do intérprete vai refletir R. Fac. Dir. UFG, V. 37, n. 02, p. 41 - 65, jul. / dez. $2013 \quad$ ISSN 0101 - 7187 
mais uma vez o que ele concebe como a melhor e mais adequada interpretação para dado objeto ou prática, uma vez consideradas as suas implicações (DWORKIN, 1986, p. 52-53).

Enquanto conceitos interpretativos, as práticas sociais demandam do intérprete uma atitude hermenêutica, que engloba dois traços distintos e independentes. O primeiro consiste em aceitar que as práticas sociais não possuem apenas uma existência factual, carregando também valores, propósitos, direcionamentos: essa característica pode ser descrita de maneira independente da regulação da prática social.

"Todos os homens devem retirar o chapéu ao entrarem na Igreja" pode nos servir como exemplo de uma prática social muito difundida em uma comunidade. A descrição da conduta, porém, é distinta do seu propósito, que pode ser a manutenção de hábitos considerados respeitosos em um espaço religioso e tradicional. O propósito é mais amplo e pode ser modificado conforme ocorram transformações na compreensão geral que a comunidade tem em torno do que é considerado respeitoso no espaço religioso.

O segundo traço consiste na observação de que a manutenção da conduta não apenas possui um propósito, mas que a conduta ela mesma precisa atender a uma interpretação preliminar desse propósito. Esse é um aspecto bem característico da atitude hermenêutica porque impede que o seguimento de uma regra se torne mecânico: não retiramos o chapéu ao entrarmos na igreja por conta da conduta em si, mas pelo valor, pelo propósito que se encontra por detrás dela e que lhe dá a devida sustentação. É esse propósito que orienta a regra, e não o contrário (DWORKIN, 1986, p. 47).

Retomando os exemplos da seção 1.1, uma discussão sobre a democracia em Cuba envolveria o conflito entre dois argumentos voltados para a defesa de duas interpretações acerca da política cubana, o que envolve a natureza da própria democracia. No primeiro caso, pode-se dizer que a restrição aos direitos fundamentais é suficiente para desclassificar Cuba como democracia, enquanto uma segunda interpretação diz que a democracia é um conceito mais amplo e envolve práticas que se situam para R. Fac. Dir. UFG, V. 37, n. 02, p. 41 - 65, jul. / dez. $2013 \quad$ ISSN 0101 - 7187 
além dos direitos protegidos, até porque eles podem existir apenas no papel, guardando pouco contato com a vida dos mais necessitados. O dado bruto, no entanto, não permite às interpretações alegar que Cuba, na verdade, é uma teocracia.

\subsection{O romance em cadeia e as suas implicações}

Em seu artigo Law as Interpretation, Dworkin ressalta novamente a relação entre o artístico e o jurídico. Dois personagens, o artista e o crítico, apontam para posturas hermenêuticas distintas, mas que adiante se entrelaçam. Ao criar a sua arte, o artista não parte do zero, mas de um conjunto de ideias que possui sobre o que é a arte e qual a forma mais adequada de se realizar uma boa arte: ele interpreta enquanto cria. Já o crítico encontra-se inserido dentro de uma comunidade acadêmica que

produz parâmetros e critérios na avaliação de um trabalho artístico, muito embora o seu "tino artístico" esteja orientado para interpretar a obra de modo que ela seja tanto melhor quanto lhe for possivel: ele cria enquanto interpreta (DWORKIN, 1982, p. 192-193).

Dworkin elabora um experimento para mostrar que ambas as funções podem se encontrar no mesmo intérprete: supondo que um grupo de romancistas venha a se reunir para a redação de um projeto literário e que cada um seja responsável por acrescentar um capítulo à trama. Para que a composição do projeto seja organizada, cada autor vai receber um número que o colocará em uma determinada posição na redação do projeto coletivo: os de número mais baixo serão responsáveis pelos capítulos de abertura e, em ordem crescente, quanto maior for o número recebido, mais tardia será a contribuição ao projeto.

Neste experimento duas posições extremas podem ser delimitadas de antemão: aquela ocupada pelos que vão iniciar o projeto e a ocupada pelos encarregados de sua conclusão. Os constrangimentos presentes na posição inicial são mínimos uma vez que não há interpretações anteriores que apontem um percurso a ser considerado pelo intérprete: cabe ao 
responsável por iniciar a investigação a tarefa complicada de apontar um rumo a ser observado pelos autores posteriores.

O autor mais recente, no entanto, precisará exercer um duplo trabalho. Primeiro, ele deve assimilar o conjunto de interpretações que o precederam atentando para a coerência presente no direcionamento apontado pelas interpretações precedentes. Sem esse passo inicial, a obra coletiva correrá o risco de tornar-se um amontoado contraditório de contribuições individuais, sendo reiniciada a cada nova contribuição. As contribuições não precisam ser similares, nem mesmo precisam concordar entre si, do contrário a própria criatividade do autor estaria sendo extinta. O crucial é que cada autor leve em consideração as contribuições precedentes em sua interpretação da cadeia, fazendo com que, em última instância, as funções de autor e intérprete, antes distintas, passem agora a serem entrelaçadas.

Supondo que, um ano após a primeira encenação do Hamlet de Shakespeare, um crítico escreva que a peça consiste em um relato histórico fidedigno dos acontecimentos ocorridos no reino da Dinamarca e apenas isso. Essa contribuição não terá atrás de si nenhuma outra interpretação, logo também não irão existir argumentos sólidos contrários a essa posição: no contexto histórico mencionado, a interpretação soa como aceitável e esclarecedora.

No entanto, se no século 21 um crítico optar por sustentar a mesma interpretação, ele precisará de argumentos muito consistentes para que a sua interpretação seja encarada como aceitável. Agora existe um gigantesco corpo de interpretações muito bem qualificadas que, apesar das múltiplas discordâncias e diferenças que possuem entre si, mostram que a riqueza do Hamlet perpassa os mais variados campos, desde indagações filosóficas até a sua enorme contribuição estética enquanto tragédia forte e única. Dizer que, na verdade, a peça é apenas um pretexto para relatar um acontecimento histórico implica em ignorar as interpretações precedentes, fazendo a leitura soar pouco plausível e fraca, já que se opõe a toda uma tendência consolidada sem fornecer argumentos para tanto. 
O romance em cadeia representa uma reformulação da interpretação jurídica ao unir uma atividade que se supõe individual, a interpretações de textos e de casos, com um empreendimento coletivo, sendo este o conjunto de decisões proferidas pelos tribunais. Estas, por sua vez, narram uma história institucional construída pela contribuição de cada um dos intérpretes: a história passa a ser um empreendimento coletivo composto por contribuições individuais. O tema dos casos difíceis e sua crítica à discricionariedade sustentada pelo positivismo jurídico, já devidamente aludido em Taking Rights Seriously, recebe aqui um tratamento peculiar (DWORKIN, 1978, p. 34).

Um problema trazido pelos casos difíceis consiste nas fontes jurídicas obrigatórias que o magistrado deve considerar ao apreciar e resolver os casos com que se defronta: quanto menor for o conjunto, maior será o âmbito de sua discricionariedade, por si só um conceito bastante complexo (DWORKIN, 1978, p. 31). Ao considerarmos a história institucional, os princípios morais e políticas sociais como fontes jurídicas a que o juiz deve recorrer, percebe-se o quanto a discricionariedade é limitada (COLEMAN; LEITER, 2000, p. 324). Os constrangimentos institucionais não são elementos específicos da decisão judicial, elementos estes que, uma vez verificados os seus limites, como ocorre nos casos difíceis, pode o magistrado deixá-los de lado e decidir conforme suas inclinações pessoais.

Os constrangimentos mencionados não apenas se encontram amplamente difundidos, como constituem também um elemento indissociável da própria decisão jurídica, como ilustra o princípio da responsabilidade política. Como qualquer oficial político, juízes são politicamente responsáveis, devendo apenas decidir quando puderem justificar a decisão recorrendo a uma teoria política que também justifica outras decisões em circunstâncias similares. A teoria política particular ao juiz estabelece uma coerência entre as suas posições tomadas em sucessivas apreciações de casos difíceis. Vejamos um exemplo apresentado por Dworkin:

Suponhamos que um parlamentar vote contra o aborto com base na crença de que a vida humana é sagrada em R. Fac. Dir. UFG, V. 37, n. 02, p. 41 - 65, jul. / dez. $2013 \quad$ ISSN 0101 - 7187 
todas as suas formas, mas que em seguida vote favoravelmente a uma lei que permite que os pais de bebês com malformações interrompam o tratamento que poderia mantê-los vivos. O parlamentar em questão poderia alegar que percebe uma diferença entre os dois casos, mas o princípio de responsabilidade estritamente aplicado não lhe permitirá esses dois votos, a menos que ele possa incorporar essa diferença em alguma teoria política geral que ele professe com sinceridade (1978, p. 87).

Ao decidir casos difíceis, o juiz precisa levar em consideração as decisões anteriores a fim de compreender as razões e motivos que as guiaram, como também o significado geral do empreendimento coletivo, o que essas decisões em conjunto querem dizer. A contribuição é menos voltada para a criatividade do magistrado, como aparentemente pode-se supor, do que pela necessidade de fazer avançar o empreendimento já iniciado. A história institucional pode fornecer ao juiz teorias conflitantes, mas comprometidas com a melhor resolução para um determinado conjunto de casos, e caberá a ele decidir por qual das duas optar.

A prática jurídica, encarada como romance em cadeia, vai demandar da decisão do juiz o preenchimento de dois elementos distintos: a decisão precisa se encaixar no romance e ao mesmo tempo fazer valer o ponto de vista do magistrado (DWORKIN, 1982, p. 194). Uma decisão se encaixa (fits) quando avalia e considera as decisões anteriores: o juiz é um intérprete e continuador da história, não um criador (BIX, 2003, p. 106). Ao mesmo tempo, no entanto, o Direito é um empreendimento político, no sentido de coordenar as inclinações individuais com as expectativas impostas pela coletividade, como também quando passa a mediar as relações entre os indivíduos e os seus governos.

$\mathrm{Na}$ medida em que interpreta ou opta por uma teoria que aponta um modo de resolver um caso difícil, cabe ao magistrado mostrar a importância nos termos do melhor princípio que a interpretação pretende consolidar. Diante da diversidade de opções que pretendem resolver um caso difícil, a escolha entre elas será uma questão para a teoria política que orienta as decisões jurídicas dos juízes, considerando tanto o Direito como 
coerente em sua totalidade quanto as metas sociais a serem contempladas (DWORKIN, 2006, p. 76 e ss).

A ampliação das fontes jurídicas faz com que Dworkin elabore a emblemática, porém controversa, tese da única resposta correta para a maioria dos casos difíceis. Considerando que, para ele, as fontes jurídicas são mais amplas do que aquelas que os positivistas consideravam, segue-se que a discricionariedade é também mais restrita (DWORKIN, 1978, p. 71). O direcionamento para a defesa de uma única resposta correta já se encontra estabelecido, apesar de ainda existirem passos importantes para um maior esclarecimento quanto ao seu uso.

Em Taking Rights Seriously, a preocupação recai no direito preexistente que uma das partes litigantes já possui e que deve ser determinado pelo magistrado. Considerando que apenas uma das partes terá esse direito, então só pode haver mesmo uma resposta correta para a pergunta formulada, muito embora a resposta não venha ser a mesma para cada juiz (DWORKIN, 1978, p. 280). Mais adiante, em Law's Empire, Dworkin flexibiliza a tese da resposta correta: nem todas as decisões judiciais precisam ser acompanhadas por uma resposta correta, uma vez que agora a prestação jurisdicional integra a própria moralidade política (MARMOR, 2000, p. 321).

Dworkin mescla o elemento estrutural (a história institucional, a comunidade liberal) com o conjunto de valores substanciais do juiz, que aí englobam a sua concepção de justiça e as metas sociais a serem reforçadas pela decisão. Neste sentido, pode-se mesmo falar em decisões conservadoras e progressistas, uma vez que a interpretação que guia as decisões terá como justificação os valores que informam caminhos a serem tomados pela sociedade como um todo. Esse é um ponto que aparece já no prefácio de Law's Empire:

A estrutura distinta e os constrangimentos presentes na argumentação jurídica surgem, nesta concepção, apenas quando nós identificamos e distinguimos as diversas e normalmente competitivas dimensões dos valores políticos, diferentes fibras entrelaçadas no juízo complexo em que uma interpretação torna a história do Direito 
melhor do que as outras, consideradas as implicações (DWORKIN, 1986, p. vii).

Uma determinada interpretação sobre a igualdade, por exemplo, diz que deve haver um maior equilíbrio na distribuição de bens econômicos e educacionais entre os membros da comunidade. A meta social consistiria na ampliação do acesso da população aos mecanismos judiciais capazes de defender os seus interesses. A melhoria na distribuição de renda pode também, conjugado com o aperfeiçoamento do sistema educacional, trazer transformações positivas nos processos eleitorais, além de uma maior discussão sobre a elaboração e aplicação das leis: todas essas consequências concorrem para um fortalecimento expressivo das práticas democráticas, isso quando concordamos com uma visão política progressista.

Outra interpretação da igualdade pode levar a uma desconsideração das desigualdades socioeconômicas, nivelando todos com base em um único critério, podendo, e há grandes chances de que isso ocorra, minimizar, ou menos eliminar, os benefícios e as conquistas que mencionamos acima. Cada qual é responsável pelo seu próprio destino, sendo a cada um encarregado de desenvolver as suas competências particulares. Basta apontar, por exemplo, o enfraquecimento das redes de proteções sociais nos Estados Unidos e na Inglaterra na década de oitenta.

A democracia não deixou de existir, é certo, mas vários problemas sociais passaram a ser repensados através de uma outra teoria política. Com o foco na atuação conservadora de alguns membros da suprema corte-norteamericana, o autor dedicou um livro sobre essa temática, o The Supreme Court Phalanx (DWORKIN, 2008, p. xii).

Ainda que o autor possua interlocutores distintos nas múltiplas discussões em que sua obra se insere, a exemplo dos utilitaristas em Taking Rights Seriously ou dos comunitaristas em Law's Empire, desde o artigo The Model of Rules I, os positivistas, principalmente os diretamente influenciados pela posição de H. L. A. Hart, permaneceram como fortes interlocutores e críticos muito sérios de sua posição. Nesta segunda parte, revisaremos as posições de Dworkin aqui apresentadas a partir das críticas fornecidas pelos 
autores que se identificam com a posição do positivista, ou com ela guardam proximidade e simpatia.

\section{Considerações criticas do positivismo jurídico a algumas posições de Dworkin}

Retornemos ao que diz Dworkin acerca das teorias semânticas do Direito: a discordância jurídica só tem lugar quando os interlocutores compartilham dos mesmos critérios para a aplicação do Direito, não sendo eles colocados em questão, limitando as discordâncias jurídicas genuínas aos casos de penumbra ou modificações legislativas. Qualquer divergência de critérios implica dizer que os interlocutores debatem entre si em línguas diversas, o que impossibilita qualquer discordância em que as partes compreendam a visão oposta (ENDICOTT, 1998, p. 284).

Um dos pontos levantados por Timothy A. O. Endicott, autor simpático ao positivismo de Hart, consiste na distinção entre uma semântica baseada em critérios (criterial semantics) e outra na interpretação (interpretive semantics). No primeiro tipo, por exemplo, o foco reside nos critérios a serem considerados para que uma determinada norma venha a ser aplicada, o que ilustramos anteriormente com o exemplo da estante de livros.

A segunda espécie de semântica estaria voltada para termos mais específicos de uma comunidade restrita, sendo o caso do Direito: contrato, obrigação, responsabilidade ganham significados e usos diversos quando empregados no contexto da prática jurídica, e por isso devem ser interpretados em conformidade com esse contexto. O argumento do aguilhão semântico deixa claro que, para Dworkin, Hart aplica a semântica baseada em critérios a todos os âmbitos do Direito (ENDICOTT, 1998, p. 284). Será mesmo?

A associação realizada por Dworkin entre Hart e a semântica baseada em critérios pode ser compreendida pela preocupação, ao menos aparente, de Hart com a definição e clarificação dos termos jurídicos, e o próprio título de seu mais emblemático livro, The Concept of Law, aponta R. Fac. Dir. UFG, V. 37, n. 02, p. 41 - 65, jul. / dez. $2013 \quad$ ISSN 0101 - 7187 
para essa direção. Sua proximidade com J. L. Austin, bem como o contato com a obra tardia de Wittgenstein através de seu colega, Friedrich Waismann, serviriam para reafirmar essa posição.

As pretensões de Hart em The Concept of Law são significativamente diversas daquelas sustentadas por Dworkin. Em seu pósescrito, Hart esclarece o objetivo de realizar uma teoria do direito geral, sendo ela descontextualizada e descritiva. Dworkin, por outro lado, concebe a teoria do direito como ancorada em uma cultura jurídica específica, normalmente a do próprio teórico, focada na apreciação/decisão jurídica. Não deixa de ser sintomático que uma de suas principais metáforas - talvez até a principal - esteja associada ao trabalho do magistrado.

Diferente de Hart, Dworkin desenvolve uma abordagem particular ao invés de geral e descritiva, tratando o Direito como fenômeno social de alta complexidade. Particular por conta do seu vínculo a uma cultura jurídica determinada, e valorativa porque simultaneamente contempla o melhor ajuste dos princípios ao direito instituído ao passo em que prescreve aos magistrados que estes venham a fornecer a melhor justificativa moral que podem proporcionar quando identificarem os princípios mencionados (HART, 2001, p. 302).

Teorias gerais como as de Hart ou Kelsen seriam inúteis já que elaboradas por um teórico situado fora de uma cultura jurídica, o que implica em um formalismo que pouco diz sobre os verdadeiros problemas que o jurista encontra em sua prática. Teorias do Direito que se pretendam úteis, diz Dworkin, consistem em interpretações de nossa própria prática jurídica historicamente situada (DWORKIN, 1986, p. 410). Hart, no entanto, destaca que Dworkin confunde o significado de um conceito, o que chamamos de semântica baseada na interpretação, com os critérios fornecidos para a aplicação correta do conceito, a chamada semântica baseada em critérios (HART, 2001, p. 307-308).

Considerando o conceito de justiça, tão importante para o próprio Dworkin, Hart introduz a distinção entre conceito e concepções, com isso mostrando que, para um dado conceito com significado estabelecido, é plenamente possível haver controvérsia acerca dos critérios que determinam R. Fac. Dir. UFG, V. 37, n. 02, p. 41 - 65, jul. / dez. $2013 \quad$ ISSN 0101 - 7187 
a sua aplicação (HART, 2001, p. 308). Hart é capaz de destacar essa controvérsia porque a sua teoria do Direito descreve o ponto de vista interno do participante, sem no entanto aderir a ele. Como Dworkin considera a teoria geral do Direito parte da prática da decisão jurídica, essa é uma possibilidade que lhe escapa.

A confusão em torno das semânticas diversas leva Dworkin a sustentar que a teoria hartiana das regras de reconhecimento fornece apenas critérios que se encerram em fatos históricos, logo os critérios de reconhecimento da lei encontram-se circunscritos aos processos consolidados das instituições jurídicas (ie. o processo legislativo), o chamado pedigree. Essa posição é conhecida por positivismo factual ou duro (hard positivism) e é também rejeitada por Hart em seu pós-escrito:

[...] em muitos sistemas de direito, tal como nos Estados Unidos, os critérios últimos de validade jurídica podiam incorporar explicitamente, para além de pedigree, princípios de justiça ou valores morais substantivos, e estes podem integrar o conteúdo de restrições jurídicoconstitucionais... Assim, a versão "semântica" do positivismo meramente factual que me atribui não é pura e simplesmente minha, nem é minha qualquer forma de positivismo meramente factual (2001, p. 312).

O positivismo moderado (soft positivism) consegue se defender de algumas das principais objeções levantadas por Dworkin, mas outras precisam ser analisadas com mais calma. Na medida em que o argumento do aguilhão semântico tem como foco expor as teorias semânticas do Direito como representações desfiguradas da prática jurídica, o positivismo moderado assimila os princípios de justiça e valores morais, como também os impasses em torno dos critérios de sua aplicação.

A limitação dos critérios fornecidos pela regra de reconhecimento ao pedigree, portanto aos constrangimentos formais, não condiz com o positivismo moderado de Hart tendo em vista que a regra de reconhecimento admite também constrangimentos materiais ao conteúdo das legislações, a exemplo das restrições que buscam proteger o direito de voto dos cidadãos imposta pela décima-nona emenda à Constituição dos Estados Unidos (HART, 2001, p. 312). A relação entre a regra de reconhecimento e a validade 
da regra é, portanto, mais ampla. Uma vez que preenche os critérios de legalidade presentes na regra de reconhecimento, uma determinada regra pode ser considerada válida, o que não necessariamente implica em produção legislativa (HART, 2001, p. 220 e ss; SHAPIRO, 2013, p. 11-12).

A posição do positivismo moderado pode soar contraditória, já que a regra de reconhecimento existe precisamente para minimizar a incerteza que paira sobre as comunidades mais primitivas, aumentando a eficiência e estabilidade do Direito em sociedades complexas, mas a alegação de que os critérios de validade jurídica devem se conformar a valores morais e princípios de justiça vai fazer retornar essa incerteza, já que valores tendem a ser difusos e potencialmente contraditórios. Um dos grandes problemas de se defender a interpretação de valores, por exemplo, reside na falta de garantia de um controle racional das decisões. Até onde uma interpretação feita sobre esse objeto pode ser considerada válida?

A objeção acima desconsidera que as próprias regras de reconhecimento podem sim ter a sua zona de penumbra. A ideia de que princípios e valores são difusos, sendo as regras claras e prontamente aplicáveis sem maiores discussões não é, portanto, uma leitura adequada da posição de Hart e do positivismo moderado. Mesmo na fictícia hipótese de que uma redação clara e precisa da lei fizesse a mesma resolver antecipadamente todos os conflitos por ela englobados, ainda assim existe a possibilidade de uma divergência entre a aplicação da lei e o conjunto de objetivos gerais que o Direito persegue (HART, 2001, p. 313).

Essa discussão vai nos levar ao tema da discricionariedade judicial e a tese de uma única resposta correta para a maioria dos casos difíceis já que trata da indeterminação relativa do Direito. Vimos como, para Dworkin, a discricionariedade seria fruto de uma concepção restrita das fontes jurídicas: Hércules, o juiz idealizado pelo autor, possui tempo o suficiente para desenvolver uma visão holística do Direito ao ponto de descobrir a resposta correta (ENDICOTT, 1997, p. 53). Cada magistrado pode, no entanto, chegar a uma resposta correta diversa, divergindo das demais, mas aqui o crucial é que o magistrado não está escolhendo uma dentre as possíveis hipóteses igualmente válidas para a resolução de um caso, mas R. Fac. Dir. UFG, V. 37, n. 02, p. 41 - 65, jul. / dez. $2013 \quad$ ISSN 0101 - 7187 
sim aquela que, conforme sua análise, é a correta, sendo as outras, portanto, inadequadas.

Um problema que advém dessa posição, segundo Brian Bix, outro autor simpático ao positivismo jurídico, consiste na demonstrabilidade da resposta correta pelo magistrado. Afinal de contas, se a resposta correta é fruto de paciência e de uma leitura holística do Direito, isso também precisa ficar claro aos jurisdicionados que vão se submeter a essa decisão, podendo até serem prejudicados por ela.

$\mathrm{Na}$ medida em que não existe um método geral para fazer com que as demonstrações sejam capazes de produzir consensos, a tese da resposta correta apresenta um problema significativo uma vez que, mesmo considerada enquanto artifício retórico daquele que decide e não mais enquanto descoberta de um Direito preexistente, parte de sua importância consiste em mostrar que a decisão jurídica não é uma construção decorrente da vontade livre do magistrado. Ao contrário, a decisão é fruto de deliberação cuidadosa, levando em consideração não apenas o conjunto das disposições normativas, mas também das decisões anteriores, ainda que não seja subordinada a elas.

Esse posicionamento novamente traz alguns impasses para Dworkin. Considerando que os juízes podem dar respostas diversas para um mesmo caso, agora nem mesmo a própria demonstração dessa resposta é garantia de produzir um consenso, ainda que hipotético. Conclui-se hipoteticamente que o resultado da adesão de uma tese como a de Dworkin será a proliferação de decisões cada vez mais divergentes sobre um mesmo caso, o que contraria a própria tese do autor: existe apenas uma resposta correta para a maioria das questões jurídicas (BIX, 2003, p. 108).

Ainda neste tópico, é preciso considerar que existe, principalmente para fins de justificação, um valor retórico considerável em se declarar que uma determinada resposta é correta, mas também que a convergência de decisões entre os magistrados é também um ponto significativo na prática jurídica. Podemos supor que os juízes, ainda que venham a divergir sobre a resposta correta, serão mais previsíveis e consistentes deste modo do que se viessem a agir discricionariamente. $\mathrm{O}$ que, ao menos em tese, justificaria R. Fac. Dir. UFG, V. 37, n. 02, p. 41 - 65, jul. / dez. $2013 \quad$ ISSN 0101 - 7187 
essa suposição é a natureza interpretativa que Dworkin atribui ao conceito de Direito: o juiz precisa interpretar o Direito em sua totalidade e da melhor maneira possível.

A suposição é difícil de sustentar uma vez que, seguindo a argumentação de Brian Bix, o desempenho da função jurídica de coordenar as ações dos jurisdicionados só faz sentido se as compreensões das orientações jurídico-normativas a que os jurisdicionados estão sujeitos venham a ser similares: eles devem entrar em acordo mais frequentemente ao predizerem como uma determinada autoridade aplicará uma regra do que se eles mesmos partirem para interpretá-la (BIX, 2003, p. 120). Ainda que os jurisdicionados tenham dificuldade em captar o sentido exato de uma disposição jurídico-normativa, eles possuem uma ideia, mesmo que vaga de como elas vão ser aplicadas pelas autoridades competentes, e que tipo de conduta eles devem adotar para entrarem em sintonia com o que fora prescrito pela norma.

Outro motivo para o enfraquecimento daquela suposição, agora pela óptica do magistrado, consiste na distorção do sentido da norma no percurso que vai desde a sua criação até o momento de sua aplicação a um caso específico. Se a distorção for plena, o juiz aplicará uma norma inteiramente diversa daquela que fora elaborada pelo legislador, algo muito improvável. O que Bix escreve sobre o sistema jurídico norte-americano vale também para o brasileiro:

Eu sustento que (para utilizar um exemplo americano) ou o juiz permanecerá fidedigno às intenções do legislativo ou o legislativo intervirá buscando esclarecer suas prévias intenções caso as leituras que os juízes façam dessas intenções sejam flagrantemente equivocadas (2003, p. 120).

Uma das objeções sustentadas por Andrei Marmor, que defende uma concepção mais dura do positivismo, no que concerne ao holismo de Dworkin, principalmente quando faz da jurisprudência uma atividade interpretativa, consiste na relação, que para Dworkin é necessária, entre interpretação e valoração. Esse movimento é muito importante para a 
posição do autor porque é precisamente aí que ele buscará se dissociar das teorias descritivas do Direito, especialmente as positivistas.

Como toda atividade interpretativa, a jurisprudência não pode deixar de ser também valorativa: o ato de interpretação só tem início quando já está formado um quadro geral de ideias sobre o objeto a ser interpretado. Não podemos, portanto, interpretar uma novela literária sem antes termos uma ideia dos valores que estruturam esse gênero. Marmor vê nesse ponto uma distinção sútil que tem consequências significativas: nós não devemos confundir a construção de uma visão sobre os valores de uma determinada prática com a formulação de um juízo valorativo acerca deles. Escreve ele:

Um antropólogo pode formular uma concepção teórica de que certo rito é valioso para as pessoas que o praticam porque melhora a coesão social sem ter qualquer juízo particular em torno do valor da coesão social, certamente não um que compete com seus juízos valorativos subjetivos (2013, p. 22).

O mesmo serviria para o teórico do direito: é preciso fazer uma distinção entre o enunciado de que o Direito é uma instituição fundada na autoridade, e a apreciação de valoração que se faz de uma autoridade particular, sendo ela legítima ou não. O problema observado por Marmor na argumentação de Dworkin é a união indissociável entre teoria e valoração: a construção de um ponto de vista teórico sobre um dado objeto não necessariamente implica em uma abordagem valorativa do mesmo.

É significativo relembrar que uma das razões que leva Dworkin a formular o argumento do aguilhão semântico consiste na desfiguração da prática pelas teorias semânticas, e que, além disso, uma teoria geral, focada apenas nas descrições formais dos sistemas jurídicos, não produz consequências produtivas: o conceito de Direito é sempre uma interpretação de um determinado tipo de prática social, e não um elemento que compõe uma questão semântica.

O problema da posição adotada por ele persiste: por que não é possível descrever os pontos de vista, valores e disposições normativas que regem uma comunidade sem necessariamente ter que vir a adotá-los? A compreensão de uma cultura estrangeira demanda um certo aprendizado de R. Fac. Dir. UFG, V. 37, n. 02, p. 41 - 65, jul. / dez. $2013 \quad$ ISSN 0101 - 7187 
valores, de regras e dos símbolos que regem as suas práticas sociais, um aprendizado que só tem como ocorrer a partir de nosso horizonte cultural, ao menos enquanto ponto de partida.

Entretanto, como sustenta Marmor, ainda que precisemos partir de nosso próprio horizonte cultural para compreendermos um outro sistema de regras e valores, daí não podemos inferir que a compreensão necessariamente vai implicar em valoração (MARMOR, 2013, p. 23). É em torno desse ponto que Hart construiu a sua famosa distinção entre o ponto de vista interno a um sistema de regras, ou seja, uma análise focada nos que se submetem a essas regras, tomando-as como guias para suas condutas, e o ponto de vista externo, em que o objetivo passa a ser a descrição das regras desconsiderando o sentido que elas possam ter para cada um dos participantes.

Como a discussão gira em torno da existência de uma relação necessária entre compreender valores e assumir uma instância valorativa, o ponto de vista externo é de pouco interesse, uma vez que ele se limita a uma descrição das regras adotadas pelos membros da comunidade. Já o ponto de vista interno é parcialmente normativo: a compreensão integra essa perspectiva uma vez que precisamos considerar as regras como componentes, razões utilizadas para uma determinada ação. Compreender uma ação implica, ao menos em parte, atentar para a regra ou o conjunto de regras utilizados se sustentar um determinado curso de ação.

Ainda assim, neste contexto, não há sequer indícios de que a compreensão implique necessariamente a tomada de um posicionamento particular no que concerne às questões morais. A relação, que para Dworkin é necessária, entre a compreensão de valores e uma atitude de valoração dificilmente se sustenta para os positivistas.

\section{Conclusão}

O debate travado entre Ronald Dworkin e H. L. A. Hart, o que incluí também os seguidores deste, foi responsável por gerar uma rica produção de artigos em torno da teoria do direito. Não apenas a temática da R. Fac. Dir. UFG, V. 37, n. 02, p. 41 - 65, jul. / dez. $2013 \quad$ ISSN 0101 - 7187 
interpretação jurídica foi reformulada, no sentido de que o conceito de interpretação não mais se encontra restrito a uma atividade normalmente associada à resolução de casos difíceis, como também a relação entre Direito e linguagem tornou-se mais complexa a partir da assimilação de vários debates oriundos da filosofia da linguagem, principalmente aqueles iniciados por Ludwig Wittgenstein e J. L. Austin.

Nos trabalhos de Dworkin, principalmente Law's Empire, encontramos uma concepção de interpretação que inscreve o Direito em uma realidade social concreta, concebendo-o como um conjunto de práticas sociais, e não como uma entidade abstrata que tem na sua estrutura formal uma de suas principais características, e ponto de análise. Essa expansão do conceito de interpretação permite não apenas uma reaproximação do Direito e da moral, como os torna inseparáveis. A análise do Direito demanda uma atitude interpretativa que remete às circunstâncias sociais particulares do intérprete, portanto a atitude é também valorativa.

Muitas das premissas que estruturaram o pensamento de Dworkin soam problemáticas aos positivistas, e estes tiveram um papel de grande importância em apontar falhas para o autor, fazendo-o modificar várias de suas posições, além de buscar novos argumentos para aquelas que ele decidiu manter. A diferença entre a tese da única resposta correta em Taking Rights Seriously e Law's Empire é emblemática.

Nos vários artigos e livros, os positivistas precisaram formular novos argumentos para sustentarem os elementos mais característicos dessa posição, como a separação entre Direito e moral, o ponto de vista descritivo e moralmente neutro, a discricionariedade judicial nos casos difíceis, dentre outros. Com o tempo, algumas dessas teses passaram a ser relativizadas dentro do próprio panorama teórico do positivismo, a exemplo da separação entre Direito e moral a partir da distinção entre soft positivism e hard positivism.

Por fim, muitas das questões debatidas pelos teóricos do positivismo jurídico e por Dworkin criaram repercussões intensas nos mais diversos campos da dogmática jurídica de vários países, inclusive o Brasil. A separação entre regras e princípios, que não pode ser compreendida de R. Fac. Dir. UFG, V. 37, n. 02, p. 41 - 65, jul. / dez. $2013 \quad$ ISSN 0101 - 7187 
maneira adequada sem aceitarmos uma concepção de fontes do Direito mais ampla, como a de Dworkin, faz-se presente em praticamente todas as áreas da dogmática jurídica brasileira.

Nenhuma das discussões levantadas por esse artigo encontra-se próxima do fim, ou mesmo se direciona para uma conclusão satisfatória. Com a morte ainda muito recente de Dworkin, os positivistas se viram privados daquele que foi, sem sombra de dúvidas, um dos seus maiores interlocutores. Resta saber qual o rumo que esses debates irão tomar, sobretudo considerando as transformações sociais e o papel cada vez maior que do Direito diante delas por conta das atuações cada vez mais notórias das cortes supremas.

\title{
A RICH AND CONTROVERSIAL RELATION: REMARKS REGARDING RONALD DWORKIN, THE POSITIVISTS AND LEGAL INTERPRETATION
}

\begin{abstract}
This present article seeks to oppose a few theoretical positions sustained by Ronald Dworkin with certain considerations from the authors theoretically affiliated with legal positivism. From the semantic sting argument through the complicated relation between Law and morals, we are going to observe how many of our taken for granted common-notions about legal practice are in fact open to discussion. These controversial discussions also had an important role in reformulating our understanding of legal interpretation, now one of the most discussed topics considering legal practice and theory. Usually related to hard cases, in which the usual normative legal dispositions were insufficient for arriving at a satisfactory solution to a case, now interpretation comprehends the whole of our legal activities, forcing us to rethink our common understanding of not only legal adjucation, but also its most important problems.
\end{abstract}

Keywords: Legal Interpretation. Legal adjucation. Dworkin. 


\section{Referências}

BIX, Brian. Law, Language and Legal Determinacy. 2. ed. Oxford: Clarendon Press, 2003.

COLEMAN, Jules; LEITER, Brian. Interpretação, Objetividade e Determinação. In: MARMOR, Andrei (org.). Direito e Interpretação. São Paulo: Martins Fontes, 2000.

DWORKIN, Ronald. Justice in Robes. Cambridge, Massachusetts: Harvard University Press, 2006.

. Law as Interpretation. In: Critical Inquiry, Vol. $9^{\circ}$, n. $1^{\circ}$, Sep/1982, pp. 179-200.

Press, 1986.

Law's Empire. Cambridge, Massachusetts: Harvard University

Taking Rights Seriously. Cambridge, Massachusetts: Harvard University Press, 1978.

. The Supreme Court Phalanx: The Court's New Right-Wing Bloc.

New York: New York Review Books, 2008.

ENDICOTT, Timothy A. O. Herbert Hart and the Semantic Sting. In: Legal Theory, v. $4^{\circ}, 1998$, p. 283-300.

63.

. Vagueness and Legal Theory. In: Legal Theory, v. $3^{\circ}, 1997$, p. $37-$

HART, H. L. A. O Conceito de Direito. 3. ed. Lisboa: Fundação Calouste Gulbenkian, 2001.

MARMOR, Andrei. Legal Positivism: Still Descriptive and Morally Neutral. Em: <http://ssrn.com/abstract=763844>. Acesso em: 28/04/2013.

. Três Conceitos de Objetividade. In: MARMOR, Andrei (org.).

Direito e Interpretação. São Paulo: Martins Fontes, 2000.

SHAPIRO, Scott J. What is the rule of recognition? Em: <http://papers.ssrn.com/abstract\#1304645>. Acesso em: 28/04/2013.

\section{Artigo submetido para avaliação em 30 de abril de 2013 e aceito para publicação em 14 de agosto de 2013.}

